\title{
BMJ
}

CHRISTMAS 2010: THE LIVES OF DOCTORS

\section{The barrier method as a new tool to assist in career selection: covert observational study}

\author{
R Scott McCain, core trainee 2, Andrew R Harris, specialty registrar 3, Kevin McCallion, consultant, W Jeffrey \\ Campbell, consultant, Stephen J Kirk, consultant
}

Department of General Surgery, Ulster Hospital, Dundonald, Belfast BT16 1RH, Northern Ireland

Correspondence to: R S McCain smccain01@qub.ac.uk

Cite this as: BMJ 2010;341:C6968 doi:10.1136/bmi.c6968

\section{ABSTRACT}

Objective To determine if senior doctors' parking habits and skills are associated with clinical specialty and, if so, whether observation of junior doctors' parking could provide guidance in choice of specialty.

Design Covert observational study.

Setting Pass-card controlled consultants' car park (parking lot), December 2009.

Participants 103 consultants entering the car park on three consecutive mornings.

Main outcome measures The outcomes were specialty and sex of the consultants, manner of approaching the barrier (pass-card ready or not), and time taken to park, exit the vehicle, and walk to a designated point.

Results Approaches to the barrier and parking were recorded for 103 consultants (79 men, 24 women): 28 anaesthetists ( 22 men, six women), 29 physicians (internists, 18 men, 11 women), 14 radiologists (nine men, five women), and 32 surgeons (30 men, two women). The manner of approaching the barrier (card ready) differed by specialty but not by sex. The total time taken to park (seconds) differed significantly between specialties: surgery (median 68, interquartile range 61-71 seconds), anaesthesia (82, 76-91), radiology (86, 70-103), and general medicine (112, 96-136). The time taken to park was overall longer among women, but this was explained by their specialty (men and women matched by specialty did not differ).

Conclusions The total time taken to park and manner of approaching the barrier to gain entry to the car park differed across specialties. Surgical consultants were fastest, followed by consultant anaesthetists and consultant radiologists, with physicians slowest. Sex was not an influencing factor. If reproducible in studies of a similar nature the "barrier method" could allow for a low cost means of guiding junior doctors in career selection.

\section{INTRODUCTION}

The selection of doctors for postgraduate training in the United Kingdom has undergone major change in recent years. Run-through training programmes leading to a certificate of completion of training aimed to ensure transparent and efficient career paths for doctors. ${ }^{1}$ To facilitate this, structured and supposedly robust selection processes were developed. The outworking of the process did not match expectation, and some specialties have since uncoupled basic specialist training from higher specialist training. ${ }^{2}$ As a result, doctors continue to be selected for a specialty at several levels of training.

Specific tools are not used to identify trainee doctors suitable for a specialty. In the UK, interview scores are the main discriminating factor, whereas elsewhere references assume more importance. ${ }^{3}$ Assessments focus on pre-existing knowledge rather than personality traits, specific ability, or aptitude needed for a particular specialty.

Despite widely held perceptions of specialty specific personality traits, it remains unclear if personality is associated with specialty. ${ }^{4-6}$ We postulated that personality traits and aptitude make a doctor suitable for a specialty and that these may be best assessed by covert observation of behaviour. Personality traits and aptitude are evident in easily observed behaviours such as driving. ${ }^{7}$ It was deemed unlikely that the local ethics committee would permit discreet observations of consultants' behaviour (or observations of indiscreet behaviour) away from the workplace.

We tested the hypothesis that an association exists between senior doctors' parking habits and skills and their clinical specialty. On this basis, observation of junior doctors' parking habits could determine their most appropriate career choice.

\section{METHODS}

We collected data prospectively in December 2009. Entries to a consultants' car park (parking lot), requiring access using an electronic pass-card, were covertly monitored on three consecutive mornings from 07.15 am to $10.30 \mathrm{am}$. This open, single level car park is entered by a private access road and provides parking for anaesthetists, physicians (internists), radiologists, and surgeons. A single observer in a hooded coat was placed at a partially concealed observation point with oversight of the access road and car park. The observer was familiar with all the consultants in the hospital and 


\begin{tabular}{lccc}
\hline $\begin{array}{l}\text { Overall time to park and manner of approach to car park, by specialty and sex } \\
\text { Specialty and sex }\end{array}$ & Sample size & $\begin{array}{c}\text { Median (interquartile range) } \\
\text { overall time (s) }\end{array}$ & $\begin{array}{c}\text { No (\%) with card ready } \\
\text { at barrier }\end{array}$ \\
$\begin{array}{l}\text { Surgery: } \\
\text { Men }\end{array}$ & 30 & $67(61-71)$ & $28(93)$ \\
\hline Women & 2 & $85(77-93)$ & $2(100)$ \\
\hline Total & 32 & $68(61-71)$ & $30(94)$ \\
\hline Anaesthesia: & 22 & $82(75-89)$ & $12(55)$ \\
\hline Men & 6 & $90(84-91)$ & $3(50)$ \\
\hline Women & 28 & $82(76-91)$ & $15(54)$ \\
\hline Total & 9 & $75(56-80)$ & $7(78)$ \\
\hline Radiology: & 5 & $100(91-121)$ & $4(80)$ \\
\hline Men & 14 & $86(70-103)$ & $11(79)$ \\
\hline Women & 18 & $109(98-120)$ & $9(50)$ \\
\hline Total & 11 & $122(97-144)$ & $3(27)$ \\
\hline General medicine: & 29 & $112(96-136)$ & $12(41)$ \\
\hline Men & & & \\
\hline Women & & & \\
\hline Total & & & \\
\hline
\end{tabular}

knew their clinical specialty. The manner of approaching the barrier was assessed and recorded as "card ready" if the entry card was visible and ready for use. A stopwatch (Casio Computer; Tokyo, Japan) was used to record the time taken (in seconds) to approach and negotiate the barrier, park the vehicle, get out of the vehicle, and walk to a designated point. We categorised the consultants by specialty and sex. The study authors were not included.

\section{Statistical analysis}

Data were collected on a Microsoft Excel spreadsheet and analysed using SPSS (version 12). We present time, expressed in seconds, as medians (interquartile ranges). The difference in manner of approaching the barrier was assessed using the $\chi^{2}$ test and Fisher's exact test. The Kruskal-Wallis one way analysis of variance was used to analyse the difference in times between all groups. When a significant difference was identified we used the Mann-Whitney-Wilcoxon test to carry out further analysis between two groups. We considered $\mathrm{P}<0.05$ to be significant.

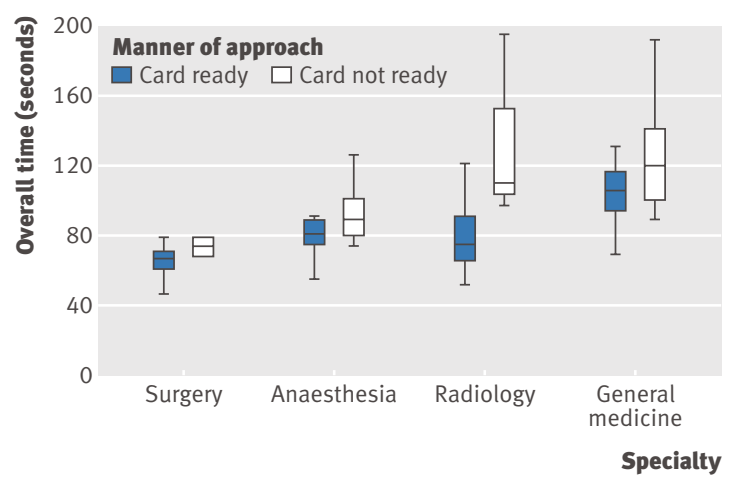

Fig 1| Overall times for manner of approaching car park barrier (pass-card ready or not) and parking, by specialty

\section{RESULTS}

Approaches to the barrier and parking were recorded for 103 consultants (79 men, 24 women): 28 anaesthetists (22 men, six women), 29 physicians (18 men, 11 women), 14 radiologists (nine men, five women), and 32 surgeons (30 men, two women). One physician was excluded as he arrived to work on a motorcycle and entered the car park through a gap in the barrier system and did not use his electronic pass. One anaesthetist, who thought the observer was a member of hospital management, protested vehemently at his presence and was excluded from the study as time had been prolonged artificially. Two consultants were excluded because they were delayed by a construction vehicle.

Overall time (seconds) differed significantly $(\mathrm{P}<0.001)$ between the specialties (table and fig 1). Surgeons were fastest (median 68, 61-71 seconds) followed by anaesthetists $(82,76-91)$ and radiologists $(86,70-103)$, with physicians the slowest $(112,96-136)$. Surgeons were fastest in all timed outcomes. The difference in each timed outcome between all specialties was significant $(\mathrm{P}<0.001$; fig 1).

Overall time to park was significantly longer among women (100, 91-130 seconds) than among men (77, $68-100 ; \mathrm{P}<0.001)$. Male and female physicians, anaesthetists, and surgeons did not differ. The difference between male $(n=9)$ and female $(n=5)$ radiologists was significant, although the numbers were small (fig 2).

The manner of approach to the barrier differed by specialty $(\mathrm{P}<0.001)$; the card was ready in $54 \%$ of anaesthetists $(n=15), 41 \%$ of physicians $(n=12), 79 \%$ of radiologists $(n=11)$, and $94 \%$ of surgeons $(n=30$; table). Men and women did not differ in their manner of approach $(\mathrm{P}=0.084)$. The differences between specialties were present regardless of the manner in which the barrier was approached (comparing specialties for overall time to park, $\mathrm{P}<0.001$ for all consultants, $\mathrm{P}<0.001$ for consultants with the pass-card ready, and $\mathrm{P}=0.002$ for consultants with the pass-card not ready; fig 3).

Confounding variables were thought to have no influence on the overall results. One anaesthetist crashed into the ticket machine. One physician approached the barrier with his head out of the driver's window to check how close he was to the kerb. Another physician was obliged to open her door to use the pass-card.

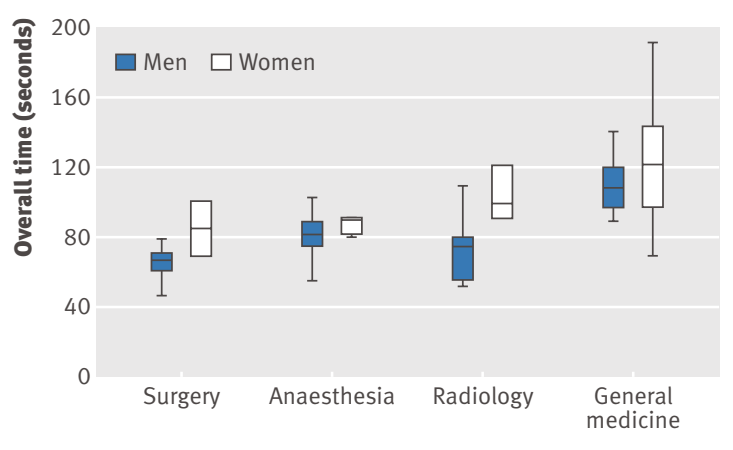

Specialty

Fig 2 Sex and overall time to parking, by specialty 


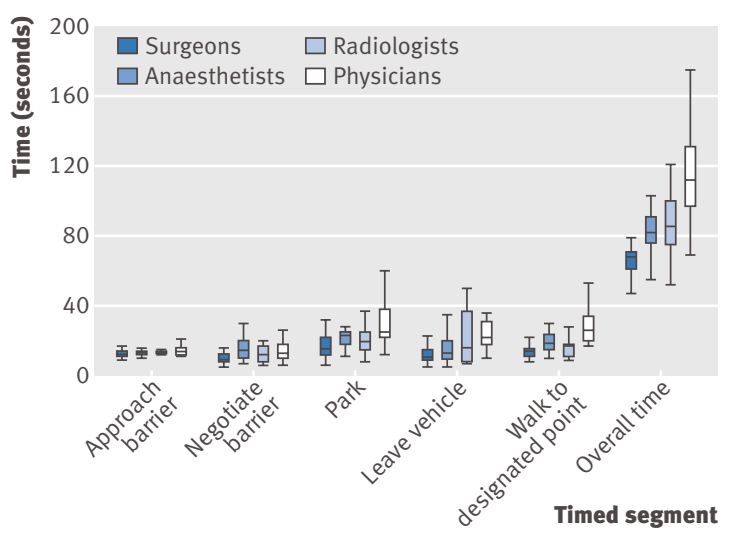

Fig 3| Manner of approach to car park barrier and overall time to park, by specialty

\section{DISCUSSION}

The covert observation of parking skills (COPS) of consultants showed that surgeons park fastest, followed by anaesthetics and radiologists, with physicians slowest. Anaesthetists and radiologists did not differ significantly. Men and women matched by specialty also did not differ significantly.

Consistency was maintained by using one observer. Few confounding variables existed. The car park is large and availability of parking was not a concern. Information on bags carried was not formally recorded, but most consultants carried at least one into work. No one carried more than two items. It was more common for surgeons than for consultants from the other specialties to carry two items, with several carrying a large bundle of radiographs in addition to a bag. This did not affect the results, as surgeons were the fastest group overall.

Although participants were blinded, the observer was not. Consultants who carried out the study were excluded from analysis. No other consultants in the hospital were aware of the study. The authors are surgeons, and although we accept that this is a potential source of bias, we believe that data were gathered accurately.

When interpreting the data we have assumed that consultants in our unit are appropriate for their specialty, but we cannot be sure that this is the case. It is unclear if personality traits seen in parking influence choice of specialty or if specialty influences personality.

\section{WHAT IS ALREADY KNOWN ON THIS TOPIC}

Selection for specialist training is controversial

No methods beyond interview are available to assist in specialty selection

Doctors' personalities may be reflected in their choice of specialty

\section{WHAT THIS STUDY ADDS}

Parking skills of consultants are associated with specialty

Parking skills are not associated with sex

The "barrier method" measured by covert observation of parking skills (COPS) may have a role in specialty selection
Furthermore, it is unclear if trainees' driving habits are well established early enough in their careers to allow for use of COPS as an assessment tool. Although we did not adjust for multiple testing, if we found a significant difference between all specialties, we further compared each specialty with all other specialties individually for all timed outcomes and overall time.

Although several authors have suggested personality and specialty are linked, no studies on parking or similar tests of aptitude have been published in the literature. Understanding how best to select for a specialty is limited. Aptitude tests may be of some benefit but are often costly, time consuming, and can be easily manipulated. No blinded method of assessing trainees for specialty selection exists.

As an aptitude test blinded to participants, the "barrier method" assessed by COPS has shown potential to provide a validated method of career selection within medicine. We have identified parking behaviours that are prevalent within certain specialties. This is a small study and was carried out in one hospital; therefore results should be interpreted with caution. Further research is necessary. We would propose that if validated in similar studies, COPS could allow objective assessment of doctors in training and provide them with clear and unequivocal guidance to assist in specialty choice.

Contributors: RSMCC designed the study, collected and analysed the data, drafted and revised the paper. He is guarantor. ARH analysed the data and drafted and revised the paper. KMCC analysed the data and revised the paper. WJC and SJK conceived and designed the study and revised the paper. None of its contents have been submitted elsewhere for publication. The authors have each been active contributors to the paper and have seen, approved, and are fully conversant with its contents.

Funding: No sources of funding.

Competing interests: All authors have completed the Unified Competing Interest form at www.icmje.org/coi_disclosure.pdf (available on request from the corresponding author) and declare: no support from any organisation for the submitted work; no financial relationships with any organisations that might have an interest in the submitted work in the previous three years, no other relationships or activities that could appear to have influenced the submitted work.

Ethical approval: Not required

Data sharing: Statistical dataset and code available from the corresponding author at smccain01@qub.ac.uk.

1 Department of Health. Modernising medical careers. The next steps. The future shape of foundation, specialist and general practice training programmes. DH, 2004.

2 Tooke J. Aspiring to excellence: findings and final recommendations of the independent inquiry into modernising medical careers. Aldridge Press, 2008.

3 Jefferis T. Selection for specialist training: what can we learn from other countries? BMJ 2007;334:1302-4.

4 Greenburg AG, McClure DK, Penn NE. Personality traits of surgical house officers: faculty and resident views. Surgery 1982;92:368-72.

5 Thomas JH. The surgical personality: fact or fiction? Am J Surg 1997;174:573-7.

6 Caldicott L. Brain maps. BMJ 2009;339:b4948.

7 Nabi H, Consoli M, Chastang J-F, Chiron M, Lafont S, Lagarde E. Type A behaviour pattern, risky driving behaviours and serious road traffic accidents: a prospective study of the GAZEL cohort. Am J Epidemiol 2005;161:864-70.

Accepted: 29 November 2010 